\title{
Representações sociais de violência no namoro em adolescentes: uma revisão sistemática
}

\author{
Social representations of dating violence in adolescents: a systematic review
}
Representaciones sociales de la violencia en el noviazgo en adolescentes: una revisión sistemática

Maria Aparecida Feitosa Candido Herculano ${ }^{1}$, Allex Alves Sobral de Souza ${ }^{1 *}$, Carmelita Maria Silva Sousa ${ }^{1}$, Lucineide Coqueiro Gurgel ${ }^{1}$, Abigail de Almeida Cordeiro ${ }^{1}$, Maria Nailê Candido Feitoza de Lima1', Maria Zildanê Candido Feitosa Pimentel ${ }^{1}$, Georgia Maria Candido Herculano', Willma José de Santana², Dayse Christina Rodrigues Pereira Luz².

\section{RESUMO}

Objetivo: Constatar através de uma revisão a existência de violência nas relações de namoro vivenciadas por jovens. Métodos: Trata-se de uma revisão sistemática com abordagem quantitativa. $\mathrm{O}$ período de busca e seleção dos artigos foi entre novembro e dezembro de 2019. Consultas foram realizadas nas bases de dados: MEDLINE, LILACS e SCIELO, por meio dos descritores "Adolescentes", "Violência" e "Sexualidade" cadastrados em Ciências da Saúde (DeCS). A seleção respeitou critérios de inclusão/exclusão dos artigos disponíveis de forma completa e gratuita, entre os anos de 2013 a 2017, no idioma português. Resultados: Foram encontrados 24.408 artigos dos quais após leitura minuciosa selecionou-se 6 artigos por cumprirem os critérios estabelecidos no estudo. Os resultados evidenciaram que pessoas do sexo masculino são as mais vitimizadas quando se trata da violência nas relações de namoro. Mostrou ainda que jovens do sexo masculino também já aparecem como vítimas desta violência; e que a violência psicológica supera os casos de violência física. Considerações Finais: A violência durante a face do namoro entre os adolescentes é um problema pouco trabalhado e divulgado no nosso país, perante esta situação, ações educativas de combate à violência no namorodevem ser adotadas como forma de prevenção a este problema.

Palavras-chave: Adolescentes, Violência, Sexualidade.

\section{ABSTRACT}

Objective: Verify through a review the existence of violence in dating relationships experienced by young people. Methods: This is a systematic review with a quantitative approach. The period of search and selection of articles was between November and December 2019. Queries were made in the databases: MEDLINE, LILACS and SCIELO, using the descriptors "Teenagers", "Violence" and "Sexuality" registered in Health Sciences (DeCS). The selection followed the inclusion / exclusion criteria of the articles available completely and free of charge, between the years 2013 to 2017, in Portuguese. Results: 24,408 articles were found, of which, 6 after reading the sumarry and introcion, 6 were selected beacause they met the criteria establiched in the study. The results showed that male people are the most victimized when it comes to violence in dating relationships. It also showed that young men also appear as victims of this violence; and that psychological violence overcomes cases of physical violence. Final Considerations: Violence during dating among teenagers is a problem that has not been dealt with and publicized in our country. Given this situation, education actions to combat dating violence should be adopted as a way of preventing this problem.

Keywords: Teenagers, Violence, Sexuality.

${ }^{1}$ Atenas College University. Orlando, Flórida - USA. *E-mail: allexsobralfisio@hotmail.com

2 Faculdade do Juazeiro do Norte (FJN). Juazeiro do Norte - Ceará. 


\section{RESUMEN}

Objetivo: Verifique a través de una revisión la existencia de violencia en las relaciones de pareja que experimentan los jóvenes. Métodos: Esta es una revisión sistemática com un enfoque cuantitativo. El período de búsqueda y selección de artículos fue entre noviembre y diciembre de 2019. Se realizaron consultas en las bases de datos: MEDLINE, LILACS y SCIELO, utilizando los descriptores "Adolescentes", "Violencia" y "Sexualidad" registrados em Ciencias de la Salud. (DeCS). La selección respetó los criterios para la inclusión / exclusión de los artículos disponibles de forma completa y gratuita, entre los años 2013 a 2017, em portugués. Resultados: Se encontraron 24,408 artículos, de los cuales, después de una lectura exhaustiva, se seleccionaron 6 artículos para cumplir con los critérios estabelecidos em el estudio. Los resultados mostraron que los hombres son los más victimizados cuando se trata de violência em las relaciones de pareja. También mostró que los hombres jóvenes también aparecen como víctimas de esta violencia; y que la violencia psicológica supera los casos de violencia física. Consideraciones finales: La violencia durante el cortejo entre adolescentes es un problema que no se ha tratado y dinfundido em nuestro país. Dada esta situación, las acciones educativas para combatir la violência em el noviazgo deberían adoptarse como una forma de prevenir este problema.

Palabras clave: Adolescentes, Violencia, Sexualidad.

\section{INTRODUÇÃO}

O conhecimento é instrumento fundamental para que o processo de interação e socialização entre indivíduos e grupos sociais venha a acontecer no contexto da sociedade. É este conhecimento, muitas vezes advindos do senso comum, que uma vez partilhado, conduz a comportamentos e posturas que fazem parte da realidade das diferentes sociedades (MOSCOVICI S, 2005). Neste cenário as Representações Sociais constituídas de explicações, opiniões, crenças, atitudes, percepções, possibilitam a compreensão dos fenômenos protagonizados pelos indivíduos, confirmando assim o que afirma, quando diz que o relacionamento das pessoas com a realidade vivenciada se dá a partir das Representações Sociais (CARMO EB e RESENDE FM, 2018).

Ao se fazer referência aos fenômenos presentes no contexto da sociedade, há que se destacar a violência, que em suas diferentes formas segue fazendo vítimas. Sabe-se que em todos os períodos da história da sociedade, há registros de violência, levando a concluir tratar-se de uma prática que trespassa todas as camadas sociais e diferentes fases vividas pela humanidade. Por assim ser, a violência se constitui em objeto de estudo, pois, ocorre em meio às relações sociais e institucionais. Sua incidência tem sido constante haja visto o número de ocorrências, em diferentes espaços geográficos, e independente da classe social, do gênero ou idade dos indivíduos envolvidos (BANDEIRA LM, 2014).

O conceito de violência traz em si diferentes interpretações, implicando assim em diversos posicionamentos teóricos além da diversidade de sugestões para solucionar ou até erradicar. Quanto às formas de violência, estas se apresentam de várias maneiras, dificultando até mesmo enumerá-las ou ordená-las. Inegável, no entanto, é o fato de que se tornou constante na sociedade, aparecendo sempre de forma diferente e ao mesmo tempo, sem que possa ser evitada (MODENA MR, 2016).

Qualquer ato de violência deixa marcas profundas, que acompanham a vítima em toda a sua vida. Tratase de um fenômeno que se constitui em motivo de reflexão e discussão independente do nível intelectual dos envolvidos ou de sua classe social. Com suas diferentes facetas, a violência se manifesta por meio de conflitos familiares, interpessoais, sociais e políticos, impactando e trazendo medo e apreensão. Vive-se em uma sociedade na qual toda e qualquer pessoa pode em um dado momento tornar-se vítima de algum tipo de violência. São agressões de diferentes formatos sejam físicos, verbais ou psicológicos, que ocorrem em diferentes ambientes. Entretanto, quando se trata do ambiente doméstico, são as mulheres suas principais vítimas (MADUREIRA AB, 2017).

A violência entre um casal dependendo de como se desenvolve a relação amorosa, em muitos casos já acontece desde a fase do namoro, mesmo acreditando-se que a violência de gênero ocorre tão somente nos relacionamentos já consolidados. Neste caso situações características do namoro não seriam 
consideradas. Porém, e apesar de poucos estudos neste sentido, é possível observar que mesmo durante o namoro entre os adolescentes, as diferenças de gênero e de seus respectivos papéis acabam solidificando determinadas posições que caracterizam a violência e sua aceitação como se assim fosse uma forma diferente de amar e por isso, aceitável durante a fase do namoro. Esse tipo de comportamento reflete a ideologia machista que permeia as relações de gênero e perpetua a violência contra o gênero feminino (SIMPSOM JA e RHOLES WS, 2017).

A vivência das primeiras experiências afetivas e sexuais se constitui em momentos de descobertas e conquistas ladeadas pelo temor de estar em desacordo com as normas que vigoram no contexto social. É a descoberta da identidade de gênero e dos papeis desenvolvidos por cada um, o que pode ter intrínseca relação com a situação de vulnerabilidade no que diz respeito a situações de vitimização ou de permanência efetiva da violência de gênero. Deduz-se ainda que a violência praticada na adolescência pode ter estreita ligação com o período da infância quando no âmbito familiar se conviveu com situações de violência conjugal materializadas em agressões que se tornam cotidianas e marcam para sempre quem nesta realidade estivesse inserido (OLIVEIRA RNG, et al., 2016).

A violência sofrida durante o namoro entre adolescentes, quando o parceiro íntimo causa algum tipo de agressão, tem ocorrido com frequência e por este motivo passou a ser objeto de estudos internacionais principalmente nos países da América do Norte, onde é atribuído o nome de "dating violence" ou "courtship violence". No cenário brasileiro, as produções cientificas abordando este assunto ainda são poucas (BRANCAGLIONII BCA e FONSECA RMGS, 2016). A violência no namoro é, de acordo com a Organização Mundial de Saúde (OMS), um "comportamento incorporado em uma relação íntima que causa dano físico, sexual e/ou psicológico, contendo atos de agressão física, coação sexual, abuso psicológico e comportamentos dominadores" (SCHEEREN P, et al., 2015).

Observando o cenário atual, o qual mostra uma sociedade que ao mesmo tempo em que se moderniza e se antena com as transformações mundiais, também convive com a estupidez da prática da violência, optou-se pela realização de um estudo, do tipo revisão sistemática, buscando assim, maior aprofundamento na temática violência entre os parceiros durante a fase do namoro. Pretende-se assim descobrir como o referido estudo: o que leva casais tão jovens a cometerem atos de violência; as formas de violência mais comum praticadas entre casais adolescentes; sentimento que permanece no agressor e no agredido; se depois de uma agressão o relacionamento se rompe de vez ou não. Neste sentido, o objetivo do estudo foi constatar a existência de violência nas relações de namoro vivenciadas por jovens.

\section{MÉTODOS}

Trata-se de em uma revisão sistemática, de cunho exploratório, natureza descritiva e de abordagem quantitativo. O levantamento sistematizado foi realizado durante os meses novembro e dezembro de 2019. O presente estudo baseou-se nos princípios metodológicos para busca dos artigos nas bases de dados eletrônicas: Sistema Online de Busca e Análise de Literatura Médica (MEDLINE), Literatura LatinoAmericana e do Caribe em Ciências da Saúde (LILACS) e Biblioteca Eletrônica Científica Online (SCIELO).

Para rastreamento dos artigos indexados nas bases de dados supramencionadas, utilizaram-se os descritores cadastrados em Ciências da Saúde (DeCS) e descritores que compõem o tema "Adolescentes", "Violência" e "Sexualidade", na língua portuguesa, sendo estes, pesquisados de forma associada, a unir utilizando o operador booleano: AND.

Para extração dos dados primários e transformação em dados secundários, foi utilizada a lista de recomendação do protocolo PRISMA, que visa ajudar os autores a melhorarem o relato de revisões sistemáticas e meta-análise. Desta forma, fez-se uso do fluxograma de quatro etapas (Identificação, seleção, elegibilidade e inclusão) que possibilita controlar o número de relatos encontrados sobre o tema pesquisado.

Foram incluídos somente estudos na língua portuguesa, o recorte temporal para seleção das publicações neste estudo foi de 2013 a 2017; Artigos completos e disponíveis, sendo citados no mínimo dois descritores utilizados no estudo. Descartaram-se aqueles desenvolvidos em crianças/adultos, falta de adequação ao objetivo de estudo, que apresentaram fuga do tema, não indexados nas bases de dados 
mencionadas, outros idiomas de publicação, artigos de revisão ou estudo de caso, duplicação de publicação, artigos não gratuitos para download, bem como aqueles que disponibilizaram somente os resumos de publicação.

\section{RESULTADOS}

Foram encontrados 24.408 artigos nas bases de dados MEDLINE, LILACS e SCIELO, após a analise metodológica, de acordo com os criterios de inclusão e exclusão, foram selecionados 6 (seis) artigos os quais se enquadraram às perpectivas do estudo. A (Figura 1) a seguir, traz a descrição destes artigos.

Figura 1 - Delineamento do estudo nas bases de dados.

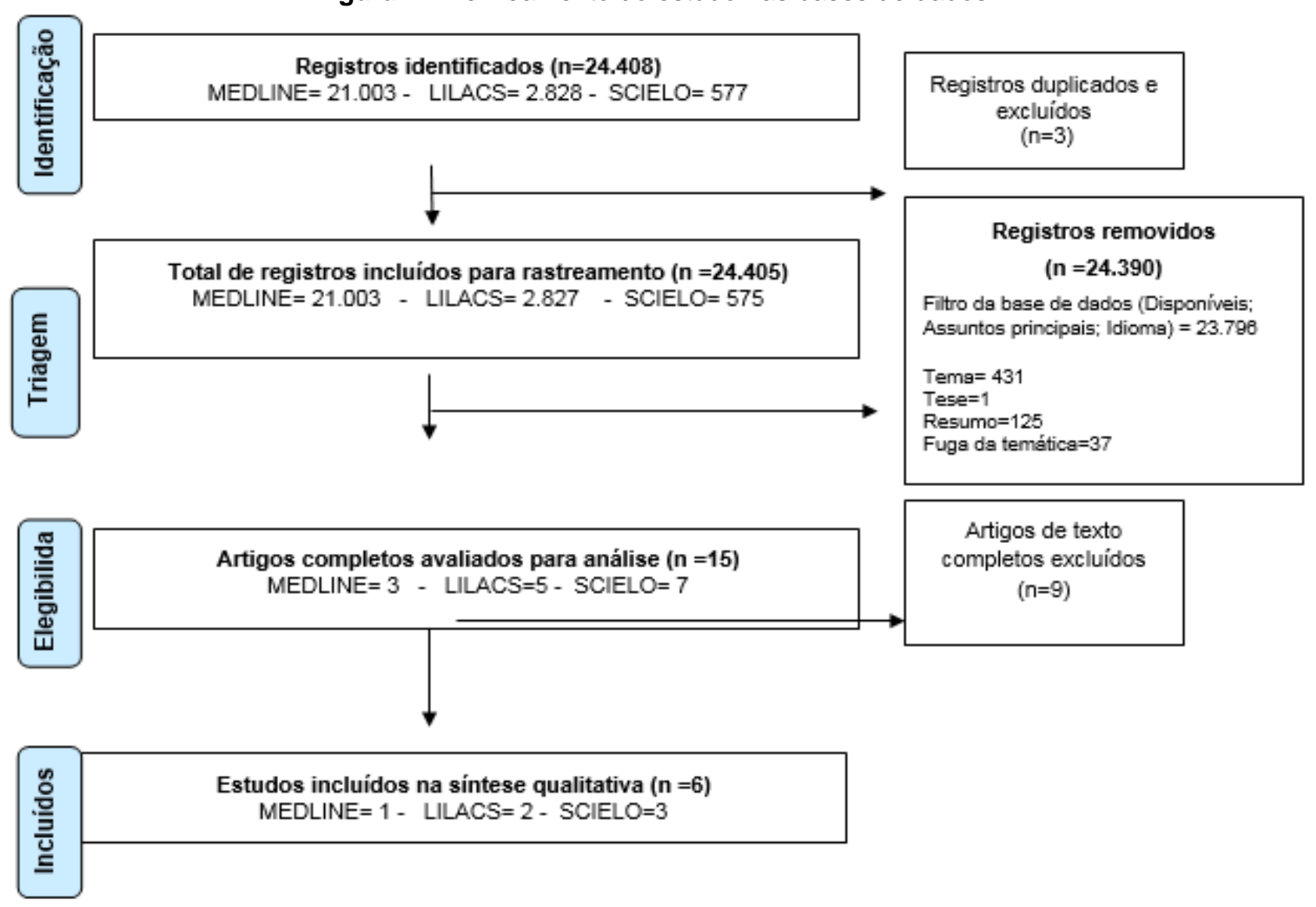

Fonte: Herculano MAFC, et al., 2020.

Conforme explicitado na metodologia, elegeu-se para análise somente artigos publicados em língua portuguesa, o que possibilitou constatar que o ano de 2013, registrou o maior número de publicações, atingindo um percentual de 33,32\%. Nos demais anos, 2014, 2015, 2016 e 2017, esse percentual é de $16,66 \%$ em cada ano. O (Tabela 1), mostra a identificação dos anos com o percentual de estudos publicados.

Tabela 1 - Descrição do idioma e anos dos artigos selecionados.

\begin{tabular}{ccccccc}
\hline \multirow{2}{*}{ Idioma } & \multicolumn{7}{c}{ Ano de publicação } & \multirow{2}{*}{$\%$} \\
\cline { 2 - 6 } & $\mathbf{2 0 1 3}$ & $\mathbf{2 0 1 4}$ & $\mathbf{2 0 1 5}$ & $\mathbf{2 0 1 6}$ & $\mathbf{2 0 1 7}$ & \\
\hline Português & $33,32 \%$ & $16,66 \%$ & $16,66 \%$ & $16,66 \%$ & $16,66 \%$ & $100 \%$ \\
\hline
\end{tabular}

Fonte: Herculano MAFC, et al., 2020.

No (Quadro 1), pode ser encontrada forma cronológica, os resultados extraídos dos artigos utilizados para a investigação. Bem como os dados retirados de cada estudo, como, autores, ano, local do estudo, amostra, métodos e desfecho. 
Revista Eletrônica Acervo Saúde / Electronic Journal Collection Health | ISSN 2178-2091

Quadro 1 - Artigos incluídos no estudo nas referidas bases de dados MEDLINE, LILACS e SCIELO 2019.

\begin{tabular}{|c|c|c|c|c|c|}
\hline № & $\begin{array}{l}\text { Autores/ } \\
\text { Ano }\end{array}$ & Local do estudo & Amostra & Métodos & Desfecho \\
\hline 1 & $\begin{array}{c}\text { Bittar DB, } \\
\text { Nakano } \\
\text { MAS, } \\
2017 .\end{array}$ & $\begin{array}{c}\text { Ribeirão Preto/São } \\
\text { Paulo }\end{array}$ & $\begin{array}{c}8 \\
\text { adolescentes } \\
\text { Femininas. }\end{array}$ & $\begin{array}{c}\text { Foi utilizada a } \\
\text { entrevista individual, } \\
\text { esta técnica } \\
\text { contribuiu para } \\
\text { desvelar as opiniões } \\
\text { e as percepções dos } \\
\text { interlocutores do } \\
\text { estudo sobre suas } \\
\text { relações afetivas no } \\
\text { namoro. }\end{array}$ & $\begin{array}{l}\text { A compreensão dos significados dados pelos adolescentes às suas relações } \\
\text { afetivas e situações de violência no namoro apontam diferentes faces da } \\
\text { violência simbólica. Marcadamente, as articulações entre masculinidade e } \\
\text { violência se apresentam com uma inflexão muito acentuada. Neste cenário de } \\
\text { associação mecânica entre o ser masculino e o ser violento, as relações de } \\
\text { gênero podem ser construídas e reproduzidas a partir de uma lógica em que a } \\
\text { violência seria a referência para se diferenciar o homem da mulher. }\end{array}$ \\
\hline 2 & $\begin{array}{l}\text { Beserra MA, } \\
\text { et al., } \\
2016 .\end{array}$ & Portugal & $\begin{array}{l}806 \\
\text { adolescentes } \\
\text { Femininos } \\
\quad 462 \\
\text { adolescentes } \\
\text { Masculinos }\end{array}$ & $\begin{array}{l}\text { Foi aplicado um } \\
\text { questionário } \\
\text { Sociodemográfico e } \\
\text { de Namoro (tempo } \\
\text { de namoro e } \\
\text { condição de ter sido } \\
\text { vítima ou não de } \\
\text { violência no } \\
\text { namoro), como } \\
\text { também se aplicou } \\
18 \text { questões que } \\
\text { avaliam os } \\
\text { comportamentos de } \\
\text { vitimização e } \\
\text { perpetração de } \\
\text { violência, ocorridos } \\
\text { no contexto das } \\
\text { relacões amorosas. }\end{array}$ & $\begin{array}{c}\text { Ambos os sexos relataram uso de violência física tais como: "Puxar os cabelos } \\
\text { com força"; "Dar uma bofetada"; "Apertar o pescoço"; "Atirar objetos em outra } \\
\text { pessoa"; "Dar pontapés e cabeçada" e "Dar empurrões violentos". A simetria da } \\
\text { violência entre namorados, ou seja, igualdade em relação ao exercício da } \\
\text { violência no namoro, que pode ser exercida tanto pelo sexo masculino quanto } \\
\text { pelo sexo feminino. }\end{array}$ \\
\hline
\end{tabular}

REAS/EJCH | Vol.12(7) | e3260 | DOI: https://doi.org/10.25248/reas.e3260.2020 Página 5 de 12 
Revista Eletrônica Acervo Saúde / Electronic Journal Collection Health | ISSN 2178-2091

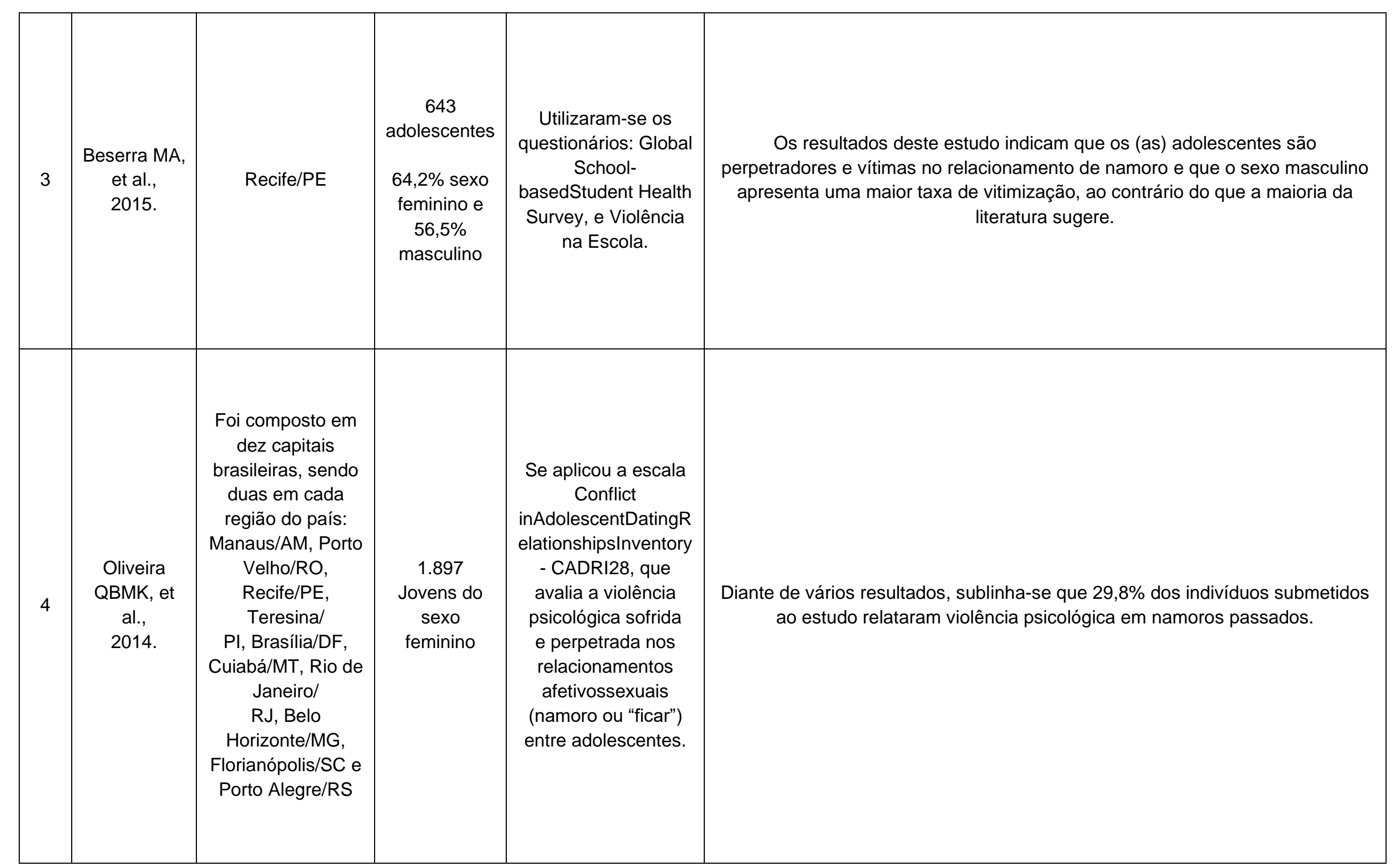

REAS/EJCH | Vol.12(7) | e3260 | DOI: https://doi.org/10.25248/reas.e3260.2020 Página 6 de 12 


\begin{tabular}{|c|c|c|c|c|c|}
\hline 5 & $\begin{array}{l}\text { Murta SGA, } \\
\text { et al., } \\
2013 \text {. }\end{array}$ & $\begin{array}{l}\text { Escola pública da } \\
\text { Cidade de Brasília }\end{array}$ & $\begin{array}{c}60 \\
\text { adolescentes }\end{array}$ & $\begin{array}{c}\text { Aplicaram-se } \\
\text { questionários para } \\
\text { coleta de } \\
\text { informações, em dois } \\
\text { grupos de } \\
\text { investigação, onde o } \\
\text { grupo controle não } \\
\text { recebeu nenhuma } \\
\text { intervenção, já o } \\
\text { grupo de intervenção } \\
\text { estava participando } \\
\text { do programa } \\
\text { (orientações obre } \\
\text { direitos sexuais e } \\
\text { reprodutivos e } \\
\text { sensibilização para a } \\
\text { atribuição desses } \\
\text { direitos a si mesmo e } \\
\text { ao outro e fez uso de } \\
\text { jogos grupais) por } \\
\text { duração de } 6 \text { meses. }\end{array}$ & $\begin{array}{c}\text { Dados interessantes sobre relacionamento e o enfrentamento com a violência, } \\
\text { expõe que a variável de violência ainda se encontra em ambos os grupos antes } \\
\text { do desenvolvimento do estudo e após sua aplicabilidade e duração, no entanto, } \\
\text { o grupo de intervenção apresentou um índice menor de relator de violência a } \\
\text { pós programa de orientação quando comparado com o grupo oposto. Evidencia } \\
\text { que medicas educativas podem se tornar um elemento para combater e/ou } \\
\text { prevenir esta causa. }\end{array}$ \\
\hline 6 & $\begin{array}{l}\text { Barreira A, } \\
\text { et al., } \\
2013 .\end{array}$ & $\begin{array}{l}\text { Cidade de } \\
\text { Recife/PE }\end{array}$ & $\begin{array}{c}320 \\
\text { Adolescentes }\end{array}$ & $\begin{array}{l}\text { Foi utilizado o } \\
\text { Conflict in } \\
\text { AdolescentDatingRel } \\
\text { ationshiplnventory - } \\
\text { Cadri para avaliar a } \\
\text { violência nos } \\
\text { relacionamentos } \\
\text { afetivos dos } \\
\text { adolescentes } \\
\text { independentemente } \\
\text { da idade do } \\
\text { parceiro/a). }\end{array}$ & $\begin{array}{c}\text { No presente estudo, observou-se que } 37 \text { meninas }(21,8 \%) \text { relataram perpetrar } \\
\text { violência física contra os seus parceiros e para violência psicológica, a } \\
\text { prevalência de perpetração foi de } 80,6 \% \text { no sexo feminino. }\end{array}$ \\
\hline
\end{tabular}

Fonte: Herculano MAFC, et al., 2020.

REAS/EJCH | Vol.12(7) | e3260 | DOI: https://doi.org/10.25248/reas.e3260.2020 Página 7 de 12 
O (Quadro 2) faz referência a comportamentos de violência perpetrada e vitimada nas relações do namoro de acordo com as falas dos adolescentes participantes das pesquisas relatadas nos artigos utilizados para essa revisão. A organização das informações nesta tabela permite melhor visibilidade em relação aos fatores desencadeantes de violência, os tipos mais comuns e se foram adotadas medidas de proteção aos que foram vítimas.

Quadro 2 - Comportamentos de violência perpetrada e vitimada nas relações do namoro referido pelos adolescentes femininas.

\begin{tabular}{|c|c|c|c|c|}
\hline № & $\begin{array}{c}\text { Fatores } \\
\text { desencadeantes }\end{array}$ & Sexo e Idade & Tipo de violência & Medidas tomadas \\
\hline 1 & Não relatou & $\begin{array}{l}\text { Feminino, entre } 15 \text { e } \\
18 \text { anos. } \\
\text { Feminino, entre } 14 \text { e } \\
18 \text { anos. }\end{array}$ & $\begin{array}{l}\text { Verbal; Física e } \\
\text { Inespecífica. }\end{array}$ & Não relatou \\
\hline 2 & Não relatou & $\begin{array}{c}56,3 \% \text { sexo } \\
\text { Feminino } \\
15 \text { a } 19 \\
\text { anos. }\end{array}$ & $\begin{array}{c}\text { Violência física e } \\
\text { verbal }\end{array}$ & Não relatou \\
\hline 3 & Não relatou & $\begin{array}{l}\text { Feminino } \\
15 \text { a } 19 \\
\text { anos. }\end{array}$ & Violência psicológica & Não relatou \\
\hline 4 & Usa roupa curta & $\begin{array}{l}\text { Feminino } \\
15 \text { a } 19 \\
\text { Anos. }\end{array}$ & $\begin{array}{l}\text { Violência simbólica, } \\
\text { psicológica, física }\end{array}$ & Não relatou \\
\hline 5 & Não relatou & $\begin{array}{c}\text { Feminino } \\
14 \text { a } 19 \\
\text { anos. }\end{array}$ & $\begin{array}{c}\text { Violência física e } \\
\text { verbal }\end{array}$ & Não relatou \\
\hline 6 & Não relatou & $\begin{array}{l}\text { Feminino } \\
12 \text { a } 18 \\
\text { anos. }\end{array}$ & $\begin{array}{l}\text { Verbal/ Moral, Física, } \\
\text { Sexual e Ameaças. }\end{array}$ & $\begin{array}{c}\text { Acabou o namoro } \\
(36 \%) \\
\text { Fez denúncia na } \\
\text { delegacia (4\%) } \\
\text { Contou aos pais } \\
(14 \%) \\
\text { Contou ao } \\
\text { professor(a) }(6 \%) \\
\text { Não fez nada (50\%) }\end{array}$ \\
\hline
\end{tabular}

Fonte: Herculano MAFC, et al., 2020.

\section{DISCUSSÃO}

Os artigos selecionados e que estão expostos no (Quadro 1), trazem a síntese, transcritas pelos pesquisadores, das falas de diferentes protagonistas adolescentes que ao seu modo relataram situações por estes vivenciadas quando das suas experiências durante o despertar do amor. São adolescentes que embora em tão tenra idade, já vivenciaram situações de agressões e violência em suas diferentes facetas.

Iniciando a etapa dos resultados e discussões, apresenta-se o estudo de Bittar DR e Nakano, MAS, (2017), trazendoo resultado de entrevistas individuais realizadasem Ribeirão Preto interior de São Paulo, na região sudeste do Brasil. Participaram do estudo 08 adolescentes do sexo feminino.

A síntese das falas, das entrevistadas mostra como essas participantes percebem as questões relacionadas ao namoro na adolescência. Em suas falas transparece o significado que cada uma atribui a tudo que envolve uma relação a dois. Quando se referem a masculinidade, fazem uma intrínseca relação entre o sexo masculino e a violência, algo que implicitamente fica posto como se a violência fosse uma 
característica do homem, tornando-se assim uma referência que diferencia o homem da mulher, evidenciando o que a própria sociedade, em decorrência do senso comum, pensa no que se refere a diferença de gênero, pontuando que em uma relação conflituosa, o homem é sempre o mais violento, e que por assim ser,passa a ser considerado superior em relação a mulher. Superioridade esta, simbolicamente advinda de um comportamento violento.

Em estudo realizado por Sartori AT, et al. (2015), conforme relato dos jovens entrevistados evidenciou-se algo que se pode considerar positivo, onde, diz respeito ao fato de que na condição de vítimas, alguns destes adolescentes põe um fim ao relacionamento abusivo e agressivo, cortando qualquer tipo de relação com o(a) ex-parceiro(a). Muitos ainda, recorrem aos seus pais e aos seus professores numa busca por apoio, proteção e segurança.

Demostrada uma realidade vivenciada pelos jovens, que embora com tão pouca idade já conviveram com a temida violência de gênero, tornando suas primeiras experiências do relacionamento a dois em uma lembrança indesejada.

A compreensão dos significados dados pelos adolescentes às suas relações afetivas e situações de violência no namoro apontam diferentes faces da violência simbólica. Este estudo aponta que mesmo na adolescência a violência aparece como uma forma de diferenciar o homem da mulher, mostrando que o ser superior da relação é sempre o sexo masculino (PRIOLO FILHO SR, 2017).

No entanto, causa preocupação e temor o fato de que grande parte dos adolescentes participantes de pesquisas sobre a violência durante o namoro, relatam que não procuram as instituições legais para que providências possam ser tomadas. Esse resultado indica que muitas das agressões sofridas ficam no silêncio, no vazio e que assim procedendo, as vítimas estarão deixando em aberto para que novas ações violentas possam ocorrer se não com elas mesmas, com outras pessoas com as quais os ex-parceiros venham a se envolver (REYES HLM, et al., 2016).

O estudo realizado por Beserra MA, et al. (2016), deu-se em Portugal, e envolveu um total de 806 adolescentes do sexo feminino e 462 adolescentes do sexo masculino. Entre as questões abordadas no questionário aplicado estavam aquelas que abordavam comportamentos de vitimização e perpetração da violência na fase do namoro.

No desfecho dos resultados os autores registraram que os participantes da pesquisa relataram diferentes formas de violência por eles sofridas. Nesse estudo, no entanto ficou evidenciado que tais atos de violência foram cometidos por ambos os sexos, mostrando assim, que em uma relação a dois na adolescência, a postura violenta passa a exercida por qualquer um dos parceiros, seja o homem ou a mulher.

Os diferentes formatos de agressões sofridas pelas vítimas de violência durante o namoro, como"Puxar os cabelos com força"; "Dar uma bofetada"; "Apertar o pescoço"; "Atirar objetos em outra pessoa"; "Dar pontapés e cabeçada" e "Dar empurrões violentos", são as atitudes mais comuns entre os jovens casais. Este cenário mostra que em qualquer uma destas situações a vítima tanto pode ser do sexo masculino quanto do feminino (BONACHE H, et., 2017).

O estudo apresentado por Beserra MA, et al. (2015), foi realizado na cidade de Recife, capital do Pernambuco, na região nordeste do Brasil. Os participantes foram 643 adolescentes, sendo $62,2 \%$ do sexo feminino e $56,5 \%$ do sexo masculino. Na conclusão dos pesquisadores fica evidenciado que as falas dos adolescentes mostram que estes são ao mesmo tempo perpetradores e vítimas da violência durante o relacionamento. No entanto, existe divergências com os demais estudos quanto aos resultados, onde, o sexo masculino aparece com maior taxa de vitimização, contrariando assim os resultados dos demais estudos nos quais o sexo feminino é que aparece com maior percentual de vitimização (BONACHE H, et al., 2016).

Os adolescentes sejam do sexo feminino ou masculino, são em situações diversas, perpetradores e vítimas no relacionamento de namoro. No entanto, em alguns casos registrados, o sexo masculino apresenta uma maior taxa de vitimização, ao contrário do que a maioria da literatura sugere. Esse indicador mostrando o sexo masculino com maior percentual de vitimização provoca uma indagação quando se tem uma realidade na qual na fase adulta o maior número de vítimas, de violência é do sexo feminino (MURTA SG, et al., 2016). 
Oliveira QBM, et al. (2014), realizaram em 1987, um estudo que abrangeu dez capitais brasileiras, distribuídas de forma a contemplar duas em ada região do país. Esta pesquisa. Tal iniciativa teve por propósito avaliar a violência psicológica sofrida e perpetrada nos relacionamentos entre adolescentes. $O$ desfecho final dos resultados registrados pelos pesquisadores, mostra que $29,8 \%$ dos participantes se colocaram como vítimas de violência psicológica sofrida em relacionamentos anteriores a realização do estudo.

A violência psicológica entre adolescentes fica marcada como lembrança dos namoros passados. Em todas as situações a violência deixa sequelas incuráveis, porém a psicológica pode alterar o comportamento da vítima causando-lhe danos irreparáveis. Onde torra-se relevante a participação das instituições educacionais, nos dois níveis de ensino (Básico e Superior), abram espaços de diálogo com adolescentes e jovens, para o debate deste assunto ligado aos relacionamentos, convivência a dois, ciúmes, violência e combate a tão famigerada prática da violência. Neste sentido, é pertinente discutir com os adolescentes e jovens, o teor da legislação brasileira que trata especificamente da violência de gênero, trazendo como principal objeto de discussão e reflexão deste tema (BAKER CK, et al., 2015).

Entre as diferentes formas de violências sofridas durante o namoro na adolescência destaca-se as: agressões físicas, por constrangimento, verbais e psicológicas. A violência física traz traumas ao corpo físico, machuca, corta, tira sangue, fere a pele e alma. A violência psicológica gera inquietude, isolamento, dor silenciosa, medo, frustação e sentimento de inferioridade. As agressões verbais trazem a vergonha e o sentimento de quem se vê xingado e desrespeitado em sua própria dignidade. Seja qual for a tipologia da violência sofrida, deixará marcas indeléveis na vítima, enquanto ao agressor nada ficará na memória, ou se ficar será como um troféu, já que o instinto violência leva a este absurdo sentimento (ANDRADE TA e LIMA $A B, 2018)$.

Murta SG, et al. (2013), desenvolveram um estudo com 60 adolescentes, na cidade de Brasília, região centro oeste do Brasil. Este estudo envolveu dois grupos de adolescentes. O grupo 1 não recebeu nenhuma intervenção do tipo orientação, aconselhamento, já o grupo 2, esse de intervenção, participava do programa de orientações obre direitos sexuais e reprodutivos e sensibilização para a atribuição desses direitos a si mesmo e ao outro. Esse trabalho de intervenção aconteceu por um período de 6 meses. Segundo registro dos pesquisadores, o grupo que participou do trabalho de intervenção apresentou um índice menor de relatos de violência quando comparado com o grupo que não teve nenhuma intervenção. Este fato mostra que ações educativas, como campanhas de orientação, esclarecimentos e estudos em grupo são instrumentos que se utilizados podem inibir comportamentos violentos sendo assim medidas de prevenção no combate a violência.

As campanhas educativas como forma de combater e/ou prevenir a violência se revelam eficazes entre os adolescentes. Com linguagens simples, porém impactantes, estas formas de abordagens educativas, indicam que estratégias como trabalhar as causas e consequências da violência através de projetos e ações junto a grupos de adolescentes podem proporcionar valiosos esclarecimentos e efetivamente colaborar para minimizar a violência entre adolescentes quando das experiências vividas no relacionamento a dois (BORREGO JL, et al., 2014).

Em estudo realizado por Conceição BRTC, et al. (2015), com estudantes de uma escola pública de Recife - PR demostrou que medidas educativas preventivas tem um papel importante no combate a violência que em muitos casos permeia o namoro adolescente, desta forma, estas intervenções educativas demostram ser os meios mais eficazes de controle e prevenção a violência durante o namoro adolescente. Onde, torna-se relevante que campanhas educativas, grupos de estudo e discussões, palestras, e relatos de experiências, são alguns dos instrumentos a serem trabalhados pelas instituições que lidam no dia a dia, com adolescentes e jovens, no combate a violência no namoro entre adolescente.

O estudo realizado em Recife-Pernambuco, por Barreira A et al. (2013), envolveu 320 adolescentes o objetivo foi para avaliar a violência nos relacionamentos afetivos dos adolescentes independentemente da idade do parceiro. Os resultados das análises dos dados encontrados, mostraram que $21,8 \%$ das meninas relataram perpetrar violência física contra os seus parceiros já em relação a violência psicológica, o maior percentual de vitimização recaiu sobre o sexo feminino, $80,6 \%$, evidenciando que as meninas exercem mais pressão psicológicas nos meninos. 
Em um estudo realizado por Fernández-Fuertes AA, et al. (2011), foi analisada a ocorrência de agressões nas relações de namoro. Os resultados mostraram que a violência verbal-emocional psicológica, aparece com maior porcentagem de vitimização e perpetração entre os participantes, quando comparada com a violência física que se apresenta em número bem menor. Os participantes dos estudos fazem parte de diferentes estados, diferentes regiões do Brasil e até de outro país, como o caso de Portugal, no continente europeu. No entanto, os adolescentes respondestes das pesquisas independente da origem, trazem em suas respostas, situações parecidas, tipos de violência semelhantes e sentimentos idênticos, mostrando assim, que a violência tem a mesma "cara", seja onde forem os lócus de ocorrência.

\section{CONSIDERAÇÕES FINAIS}

A abundância de elementos que permitem refletir acerca da percepção dos adolescentes sobre a violência de gênero durante a fase do namoro e das suas primeiras experiências em um relacionamento a dois propõe uma vasta discussão sobre o tema. Quanto as características dos principais tipos de violências sofridas durante o namoro na adolescência, observa-se uma diversidade de formas de violência cometida e sofrida por adolescentes durante o namoro. Estes atos se constituem de agressões físicas, psicológicas, verbais, constrangimento entre outras, sendo que as físicas e as psicológicas são as mais recorrentes. Conclui-se que medidas devem ser adotadas no sentido de identificar e combater a violência e suas consequências entre jovens durante a fase do namoro adolescente.

\section{REFERÊNCIAS}

1. ANDRADE TA, LIMA AB. Violência e namoro na adolescência: uma revisão de literatura. DESIDADES: Revista Eletrônica de Divulgação Científica da Infância e Juventude. 2018; 19(6).

2. BANDEIRA LM. Violência de gênero: a construção de um campo teórico e de investigação. Soc. Estado, Brasília. 2014; 29(2).

3. BAKER CK, et al. The relation ship between self-harm and teen dating violence among youth in Hawaii. Qualitative Health Research. 2015; 25(5): 652-667.

4. BARREIRA AK, et al. Coocorrência de violência física e psicológica entre adolescentes namorados do Recife, Brasil: Prevalência e fatores associados. Ciência \& Saúde Coletiva. 2013; 18(1): 233-243.

5. BESERRA MA, et al. Prevalência de Violência no Namoro entre Adolescentes de Escolas Públicas de Recife/Pe Brasil.Revista de Enfermagem Referência. 2015; 6(7).

6. BESERRA MA, et al. Prevalência e características da violência no namoro entre adolescentes escolares de Portugal. Escola Anna Nery. 2016; 20(1): 183-191.

7. BITTAR DB, NAKANO AMS. Violência simbólica entre adolescentes nas relações afetivas do namoro. Rev. Esc. Enferm. USP. 2017; 51(1): 01-08.

8. BONACHE H, et al. Adult attachment styles, destructive conflict resolution, and the experience of intimate partner violence. Journal of Interpersonal Violence. 2016; 34(2): 287-309.

9. BONACHE H, et al. Romantic attachment, conflict resolution styles, and teen dating violence victimization. Journalof Youth and Adolescence. 2017; 46(9): 1905-1917.

10. BORREGO JL, et al. Violencia em el noviazgo: revisión bibliográfica y bibliométrica. Arquivos Brasileiros de Psicologia. 2014; 66(1): 1-17.

11. BRANCAGLIONI BCA, FONSECA RMGS. Violência por parceiro íntimo na adolescência: uma análise de gênero e geração Rev. Bras. Enferm. 2016; 69(5): 890-898.

12. CARMO EB, RESENDE FM. Representações sociais e o processo de construção de identidades homossexuais: identificando e comparando as representações de homens homossexuais e homens heterossexuais sobre a homossexualidade masculina. Revista da Graduação em Psicologia da PUC Minas. 2018; 3(5).

13. CONCEIÇÃO BRTC, et al. O ciúme romântico entre gêneros: uma visão sociopsicológica. Rev Psicol Foco. 2015; 7(9): 53-66.

14. FERNÁNDEZ-FUERTES AA, et al. Características del comportamento agressivo en las parejas adolescentes españoles. Behavioral Psychology/Psicología Conductal, 2011; 501-522.

15. MADUREIRA AB. Representações sociais sobre violência conjugal por homens acusados no contexto da Lei Maria da Penha. Tese de Doutorado. Programa de Pós-Graduação em Enfermagem, Setor de Ciências da Saúde. Universidade Federal do Paraná. Curitiba. 2016.

16. MOSCOVICI S. Representações sociais: investigações em psicologia social. 3.ed. Petrópolis: Vozes, 2005.

17. MODENA MR. Conceitos e formas de violência. Caxias do Sul, RS. Educs, 2016.

18. MURTA SG, et al. Prevenção à violência no namoro e promoção de habilidades de vida em adolescentes. Psicologia USP, São Paulo. 2013; 24(2): 263-288.

19. MURTA SG, et al. Efeitos de um programa de prevenção à violência no namoro. Psico-USF, 2016; 21 (2): $381-393$.

20. OLIVEIRA QBM, et al. Violência nas Relações Afetivos-Sexuais. In: MINAYO, M. S. C.; ASSIS, S. G.; NJAINE, K. Amor e Violência um paradoxo das relações de namoro e do 'ficar' entre jovens brasileiros. Rio de Janeiro, Fiocruz. 2011. 
21. OLIVEIRA QBM, et al. Namoro na adolescência no Brasil: circularidade da violência psicológica nos diferentes contextos relacionais. Ciência \& Saúde Coletiva. 2014; 19(3): 707-718.

22. OLIVEIRA RNG, et al. A prevenção da violência por parceiro(a) íntimo(a) na adolescência: uma revisão integrativa. Rev. Esc. Enferm. USP. 2016; 50(1): 134-43.

23. PRIOLO FILHO SR. Violência no namoro: avaliação de um programa de prevenção. São Carlos, SP. Tese de Doutorado, Universidade Federal de São Carlos-UFSCar. 2017; 116.

24. REYES HLM, et al. Gender role atitudes and male adolescent dating violence perpetration: normative beliefs as moderators. J Youth Adolesc. 2016; 45(2): 350-360.

25. SARTORI AT, et al. Posições enunciativas entre namorar e ficar: jovens escrevendo na escola. RevProlíngua. $2015 ; 10(2): 25-36$.

26. SCHEEREN P, et al. O papel preditor dos estilos de apego na resolução do conflito conjugal. Estudos e Pesquisas em Psicologia. 2015; 15(3): 835-852.

27. SIMPSOM JA, RHOLES WS. Adult attachment, stress, and romantic relationships. Current Opinion in Psychology. 2017; 13: 19-24. 